\title{
Naissance de la critique dramatique, L. Michel et C. Bourqui (dir.)
}

\section{Monica Pavesio}

\section{(2) OpenEdition}

1 Journals

\section{Edizione digitale}

URL: http://journals.openedition.org/studifrancesi/10560

DOI: 10.4000/studifrancesi. 10560

ISSN: 2421-5856

\section{Editore}

Rosenberg \& Sellier

\section{Edizione cartacea}

Data di pubblicazione: 1 décembre 2017

Paginazione: 547

ISSN: 0039-2944

\section{Notizia bibliografica digitale}

Monica Pavesio, «Naissance de la critique dramatique, L. Michel et C. Bourqui (dir.)», Studi Francesi [Online], 183 (LXI | III) | 2017, online dal 01 février 2018, consultato il 23 janvier 2021. URL: http:// journals.openedition.org/studifrancesi/10560 ; DOI: https://doi.org/10.4000/studifrancesi. 10560

Questo documento è stato generato automaticamente il 23 janvier 2021.

\section{(c) (i) (9)}

Studi Francesi è distribuita con Licenza Creative Commons Attribuzione - Non commerciale - Non opere derivate 4.0 Internazionale. 


\title{
Naissance de la critique dramatique, L. Michel et C. Bourqui (dir.)
}

\author{
Monica Pavesio
}

\section{NOTIZIA}

Naissance de la critique dramatique, sous la direction de Lise MICHEL et Claude BOURQUI, «Littératures classiques» 89, 2016, 207 pp.

1 Dopo il 1650, si elabora in Francia un nuovo discorso sulle opere teatrali incentrato sulla ricezione delle opere teatrali e sulla critica degli spettatori. La critica teatrale continua a svilupparsi nei paratesti delle pièces pubblicate e nei trattati consacrati alle arti dello spettacolo, ma si diffonde anche nelle Gazettes di Loret e di Robinet, nel Mercure galant, nella Gazette d'Amsterdam, nonché nelle relazioni dei viaggiatori e dei diplomatici, permettendo la diffusione delle reazioni che gli avvenimenti teatrali hanno suscitato negli spettatori.

2 Secondo i curatori del volume, due specialisti del teatro francese del XVII secolo Lise Michel e Claude Bourqui, a partire dagli anni Cinquanta, la critica teatrale invade i salotti mondani, appropriandosi dei valori e della terminologia in essi utilizzata. L'interesse si sposta sugli aspetti materiali delle rappresentazioni, sui costumi, sugli accessori, sui gesti degli attori, sui sentimenti che gli spettacoli suscitano negli spettatori. Nascono quindi nuovi criteri di giudizio, fondati sui sentimenti degli spettatori, che non sono ridotti a delle pure e semplici opinioni personali, ma si accordano e si armonizzano con quelle degli altri.

3 La coscienza di questa nuova forma di critica nasce dopo il 1660, quando si forma un nuovo principio di legittimazione progressivo di questo fenomeno che il presente volume di Littératures classiques si propone di indagare.

Il primo contributo di E. BURY (De l'ars critica à la critique dramatique: un dialogue de sourds?, pp.17-29) si interroga sui fondamenti del fenomeno della critica drammatica nascente, nella sua articolazione con la nozione stessa del termine "critique", nato 
nell'Antichità e affermatosi nell'Umanesimo, che presuppone una presa di distanza dall'opera che si vuole giudicare, estranea alla nuova tendenza che si afferma in Francia dopo la metà del xviI secolo.

Tre contributi si focalizzano direttamente o indirettamente su un episodio decisivo della nuova critica, come la ricezione della Sophonisbe di Corneille: nel Discours sur la Sophonisbe, pubblicato nel 1663, nelle Nouvelles Nouvelles di Jean Donneau de Visé (Ch. SCHUWEY e A. VUILLEUMIER, Les conditions de possibilité de la critique dramatique au XVII siècle: le cas du discours de Donneau de Visé sur la "Sophonisbe" pp. 31-41); nella Querelle che ne seguì (C. MELI, La critique dramatique à l'épreuve de la polémique: l'abbé d'Aubignac et la querelle de "Sophonisbe" pp. 43-54) e nell'utilizzo del nome di "Corneille" come genere, piuttosto che come autore, nella querelle e nei dibattiti dell'epoca (M. EscolA, Au nom de Corneille. L'auteur comme genre pp. 55-72). Un contributo è dedicato alla ricezione del Tartuffe (C. Ріот, Le "Tartuffe" de Molière sous l'œil de ses premiers spectateurs pp. 115-129).

6 La prospettiva si allarga, poi, da un punto di vista geografico con i discorsi degli ambasciatori stranieri alla corte di Francia (E.R. WELCH, La critique des spectacles par les diplomates au XVII siècle pp.103-114) e dei viaggiatori francesi su alcune rappresentazioni in Inghilterra (B. LOUVAT-MOLOZAY e A. DÉLÉRIS, Le théâtre anglais vu par les voyagers français dans les années 1660 , pp. 87-102) e da un punto di vista storico, sociologico e di genere: esistenza di una voce critica femminile (V. LOCHERT, Y-a-t-il une critique féminine? Représentations du jugement des spectatrices dans le théâtre français du XVII siècle pp. 75-86); il ruolo della concorrenza (S. BLONDET, Critique et concurrence dramatique durant la décennie 1630 pp. 147-158); i dati dei registri della Comédie-Française (S. HARVEY, Sens et pouvoir de l'assemblée théâtrale. La critique dramatique dans le Mercure galant et les registres journaliers de la Comédie-Française (1680-1700) pp. 175-188); il nuovo genere della "comédie de spectateurs" (J.M. HosTIOU, La critique dramatique au miroir des comédies de spectateurs chez les héritiers de Molière pp.131-143). Vengono stabiliti, per finire, dei legami con delle altre forme di critica nel campo della musica (L. NAUDEIX, La première querelle de la musique italienne: prémices d'une critique du spectacle musical pp. 189-200) e della pittura (B. SELMECI CASTIONI, De la loge de l'ambassadeur à l'éloge paradoxal. Naissance de la critique dramatique illustrée dans le "Mercure galant" (1682) pp. 159-173).

Il volume si inserisce nel progetto "Naissance de la critique dramatique", finanziato dal fondo nazionale svizzero per la ricerca scientifica anni 2013-2016, che si propone di repertoriare le nuove forme di discorso sul teatro nel momento in cui lo spettatore da destinatario del discorso ne diventa la fonte. Il sito del progetto, www. ncd17.ch, contiene più di un migliaio di estratti di testi teatrali. 